\title{
EVALUASI PENERAPAN KRITERIA GREEN AND SMART BUILDING PADA PROYEK PEMBANGUNAN GEDUNG KANTOR PT. INALUM (PERSERO)
}

\author{
Muhammad Fadel Andika ${ }^{1}$, Fadhil Putra Noviadi ${ }^{2}$, Darman Ferianto Saragih ${ }^{3}$ \\ ${ }^{1}$ Program Studi Manajemen Rekayasa Konstruksi Gedung, Politeknik Negeri Medan \\ Email: muhammadandika@students.polmed.ac.id \\ ${ }^{2}$ Program Studi Manajemen Rekayasa Konstruksi Gedung, Politeknik Negeri Medan \\ ${ }^{3}$ Program Studi Teknik Perancangan Jalan dan Jembatan, Politeknik Negeri Medan
}

\begin{abstract}
Abstrak. Konsekuensi dari proses pembangunan, operasi dan pemeliharaan sebuah gedung adalah penggunaan sumber daya alam, energi serta dihasilkannya limbah yang dapat mengganggu harmonisasi alam. Salah satu upaya yang dapat dilakukan untuk menangani kondisi tersebut adalah konsep penerapan Green and Smart Building. Berdirinya lembaga Green Building Council (GBC) Indonesia yang merupakan upaya pemerintah dalam menggalakkan konsep bangunan gedung ramah lingkungan yang mampu mengatasi dampak pembangunan. Pada penelitian iniini dilakukan penilaian kriteria Green and Smart Building pada gedung kantor PT. INALUM (Persero) yang bertujuan untuk mengetahui sejauhmana tingkat keberhasilan penerapan Green and Smart Building pada proyek pembangunan gedung kantor PT. INALUM (Persero). Penelitian ini dilakukan dengan cara observasi dan wawancara serta pengumpulan data sekunder dari pihak perencana dan pelaksana meliputi gambar rencana, dokumen perencanaan, dokumen AMDAL (Analisa Mengenai Dampak Lingkungan), RKS (Rencana Kerja Syarat-syarat) yang kemudian dilakukan analisis komparatif untuk membandingkan antara data yang didapatkan dengan standar penilaian Greenship untuk Bangunan Baru Versi 1.2. Berdasarkan hasil analisis data, didapatkan indeks nilai penilaian Green Building pada gedung kantor PT. INALUM (Persero), total poin yang diperoleh sebesar 66 poin dari tolal 101 poin maksimal dan memperoleh persentase sebesar 65,35 $\%$. Berdasarkan tingkat predikat Greenship, Gedung Kantor PT. INALUM (Persero) memperoleh predikat emas.
\end{abstract}

Kata kunci: Green Building, Smart Building, GBC Indonesia, Greenship, PT. INALUM (Persero).

Diterima Redaksi: 03-10-2020 | Selesai Revisi: 09-03-2021 | Diterbitkan Online: 09-03-2021

\section{PENDAHULUAN}

Pembangunan sebuah gedung berdampak besar terhadap lingkungan hidup. Hal ini karena bangunan adalah entitas besar, dimana konsekuensi dari proses pembangunan sebuah gedung adalah penggunaan sumber daya alam dan energi serta dihasilkannya limbah yang dapat mengganggu harmonisasi alam.

Potensi kerusakan lingkungan yang diakibatkan oleh bangunan dimulai dari tahap pemilihan lahan. Lokasi bangunan menentukan berapa banyak jejak ekologi yang akan diganggu. Jika dibangun dilahan hijau alami, maka habitat dari tumbuhan dan hewan yang sebelumnya menempati ekosistem tersebut akan terancam lalu mencari habitat baru atau bahkan musnah. Hal ini mengancam biodiversitas. Memasuki tahap konstruksi, pembangunan akan mengkonsumsi material dan energi dalam jumlah yang relatif besar. Material yang digunakan berasal dari pengerukan sumber daya alam dan produk manufaktur yang juga menghasilkan limbah ke lingkungan. Selanjutnya, memasuki tahap operasi dan pemeliharaan bangunan. 
Isu lingkungan yang nyata adalah konsumsi energi listrik, konsumsi air dan limbah.

Salah satu upaya yang dapat di lakukan untuk menangani kondisi tersebut adalah penerapan konsep Green and Smart Building. Berdirinya lembaga Green Building Council (GBC) Indonesia sebagai lembaga sertifikasi yang diakui secara internasional yang merupakan upaya pemerintah dalam menggalakkan konsep bangunan gedung yang ramah lingkungan yang mampu mengatasi dampak pembangunan. Oleh karena itu, perlu adanya penelitian lebih lanjut tentang penerapan Green and Smart Building pada gedung-gedung di Sumatera Utara agar dapat dijadikan sebagai langkah awal program Green and Smart City dan untuk kelangsungan generasi yang akan datang.

Green Building atau bangunan hijau adalah bangunan gedung yang memenuhi persyaratan bangunan gedung dan memiliki kinerja terukur secara signifikan dalam penghematan energi, air, dan sumber daya lainnya melalui penerapan prinsip bangunan gedung hijau sesuai dengan fungsi dan klasifikasi dalam setiap tahapan penyelenggaraannya. Smart Building atau bangunan cerdas adalah bangunan Gedung yang mampu mengintegrasikan antara sistem bangunan, teknologi, dan energi. Sistem ini dapat mencakup otomatisasi bangunan, keselamatan pengguna, telekomunikasi, dan manajemen fasilitas.

\section{METODE PENELITIAN}

Tahapan-tahapan dalam penelitian sesuai diagram alir penelitian seperti pada Gambar 1 berikut.

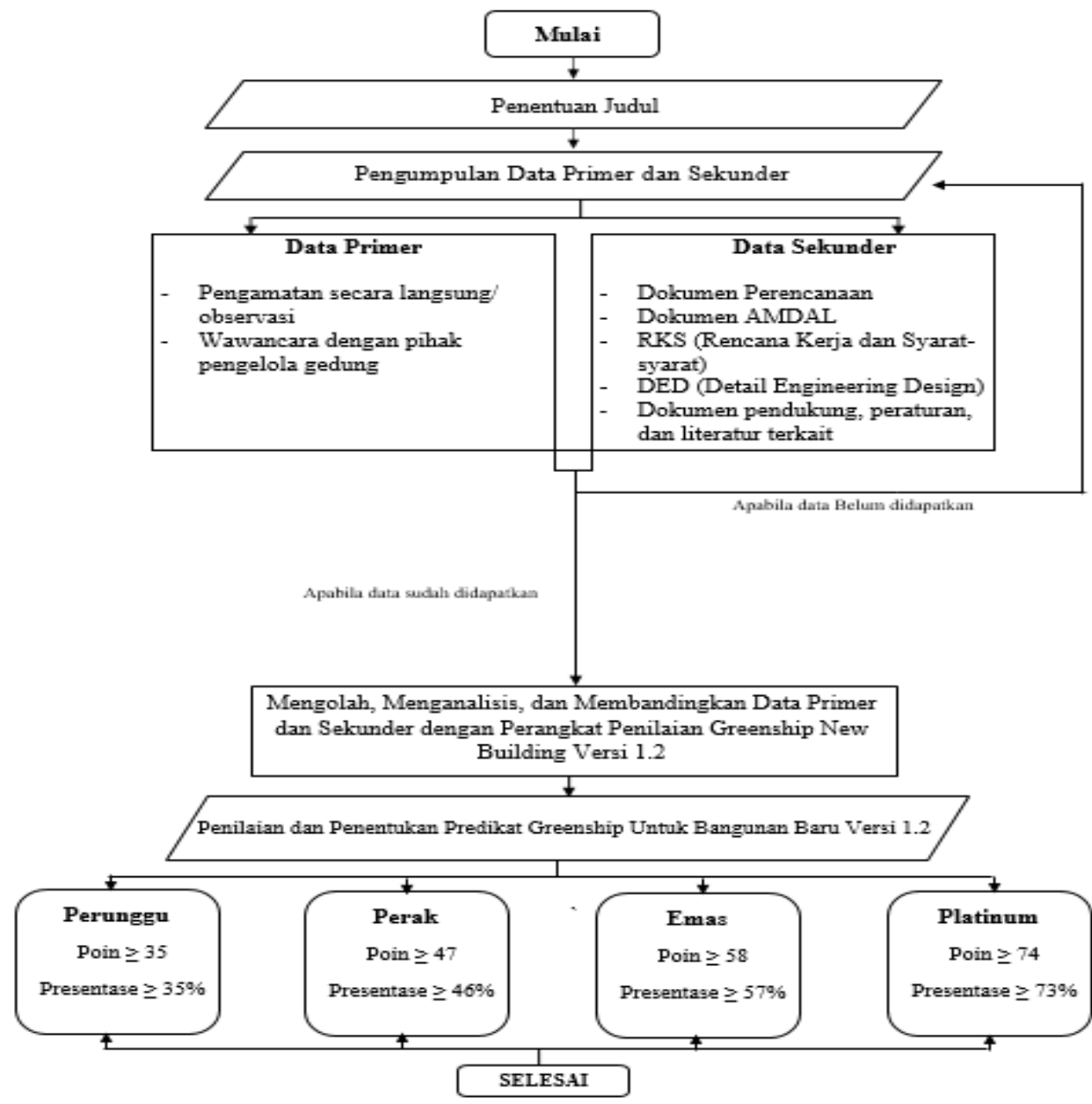

Gambar 1. Diagram Alir Penelitian 


\section{HASIL DAN PEMBAHASAN}

\section{Syarat Kelayakan Bangunan}

Diperoleh hasil seperti Tabel 1 berikut:

Tabel 1. Syarat Kelayakan Bangunan

\begin{tabular}{cccc}
\hline No & Kriteria & Memenuhi & Tidak Memenuhi \\
\hline 1. & Luas minimum gedung adalah $2500 \mathrm{~m}^{2}$ & - \\
2. & Fungsi gedung sesuai dengan peruntukan lahan berdasarkan & $\checkmark$ & - \\
RT/RW & Memiliki dokumen lingkungan, AMDAL, dan/atau UKL-UPL & $\checkmark$ & - \\
4. Kesesuaian gedung terhadap standar keselamatan untuk kebakaran & $\checkmark$ & - \\
5. & Kesesuaian gedung terhadap standar ketahanan gempa & $\checkmark$ & - \\
6. & Kesesuaian gedung terhadap standar aksesibilitas penyandang & $\checkmark$ & \\
\hline
\end{tabular}

\section{Analisis Prasyarat Perangkat Penilaian Greenship Untuk Gedung Baru}

Prasyarat Perangkat Penilaian Greenship untuk Gedung baru terhadap Gedung Kantor PT. Inalum (Persero) diperoleh hasil seperti Tabel 2.

Tabel 2. Prasyarat Perangkat Penilaian Greenship Untuk Gedung Baru

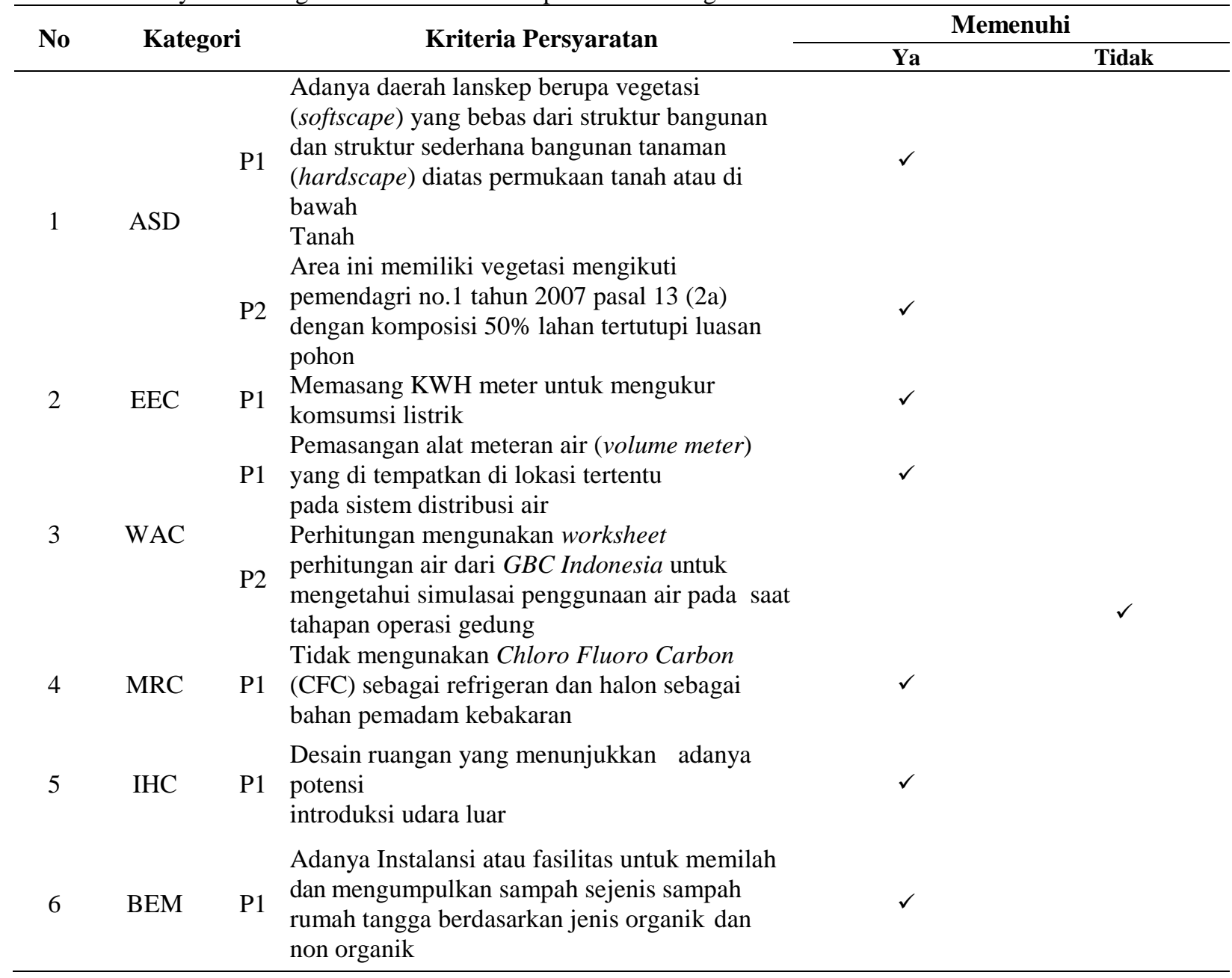




\section{Analisis Kesesuaian Kriteria dalam Greenship di Gedung Kantor PT. Inalum (Persero)}

1. Kategori tepat guna lahan sesuai, Tabel 3.

Tabel 3. Ringkasan Kategori tepat guna lahan

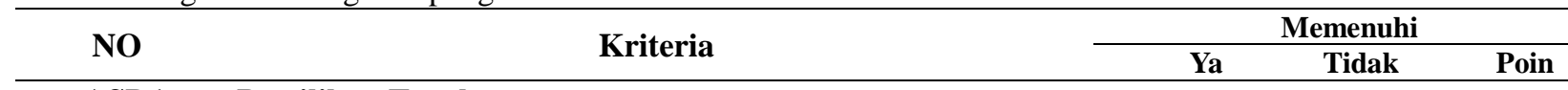

ASD1 Pemilihan Tapak

Memilih daerah pembagunan yang di lengkapi minimal 8 dari 11 prasarana sarana kota

1. Jaringan jalan

2. Danau buatan

1

3. Jaringan penerangan dan listrik

7. Sistem pembuangan sampah

8. Jaringan telepon

9. Sistem pemadam kebakaran

4. Jalur pejalan kaki

10. Jaringan air bersih

5. Jaringan drainase

11. Jaringan fiber optic

6. Jalur pemipaan gas

Melakukan revitalisasi dan pembangunan di atas lahan yang

2 bernilai negatif dan tak terpakai karena bekas pembangunan atau dampak negatif pembangunan

\section{ASD2 Aksesibilitas Komunitas}

Terdapat minimal tujuh jenis fasilitas umum dalam jarak pencapaian jalan utama sejauh $1500 \mathrm{~m}$ dari tapak.

1. Bank

2. Taman Umum

3. Parkir Umum

14 . Warung

5. Gedung Serba Guna

6. Pos Keamanan / polisi

7. Tempat Ibadah

8. Tempat Olah Raga

9. Tempat Penitipan Anak

10. Apotek

Membuka akses pejalan kaki selain ke jalan utama di luar tapak yang menghubungkannya dengan jalan sekunder dan/atau lahan milik orang lain sehingga tersedia akses ke minimal tiga fasilitas umum sejauh $300 \mathrm{~m}$ jarak pencapaian pejalan kaki.

Menyediakan fasilitas/akses yang aman, nyaman, dan bebas dari perpotongan dengan akses kendaraan bermotor untuk

3 menghubungkan secara langsung bangunan dengan bangunan lain, di mana terdapat minimal tiga fasilitas umum dan/atau dengan stasiun transportasi masal.

Membuka lantai dasar gedung sehingga dapat menjadi akses 4 pejalan kaki yang aman dan nyaman selama minimum 10 jam sehari.

\section{ASD3 Transportasi Umum}

Menyediakan Shuttle bus untuk penguna tetap gedung dengan jumlah unit minimum untuk $10 \%$ pengguna tetap gedung

Menyediakan fasilitas jalur pedestrian di dalam area gedung untuk menuju ke stasiun transportasi umum terdekat yang aman dan nyaman

\section{ASD4 Fasilitas Pengguna Sepeda}

$$
\text { Kantin }
$$

13. Fasilitas Kesehatan

14. Kantor Pos

Kantor Pemadam Transportasi Umum

17. Perpustakaan

18. Kantor Pemerintah

19. Pasar dari bangunan taman (hardscape) yang terletak di atas permukaan 


\begin{tabular}{|c|c|c|c|c|}
\hline \multirow{2}{*}{ NO } & \multirow{2}{*}{ Kriteria } & \multicolumn{3}{|c|}{ Memenuhi } \\
\hline & & Ya & Tidak & Poin \\
\hline & $\begin{array}{l}\text { tanah seluas minimal } 40 \% \text { luas total lahan. Luas area yang } \\
\text { diperhitungkan adalah termasuk yang tersebut di Prasyarat } 1 \text {, } \\
\text { taman di atas basement, roof garden, terrace garden, dan wall } \\
\text { garden }\end{array}$ & & & \\
\hline $1 \mathrm{~B}$ & $\begin{array}{l}\text { Bila tolok ukur } 1 \text { dipenuhi, setiap penambahan } 5 \% \text { area } \\
\text { lansekap dari luas total lahan mendapat } 1 \text { nilai. }\end{array}$ & $\checkmark$ & & 1 \\
\hline 2 & $\begin{array}{l}\text { Penggunaan tanaman yang telah dibudidayakan secara lokal } \\
\text { dalam skala provinsi }\end{array}$ & $\checkmark$ & & 1 \\
\hline ASD6 & Iklim Mikro & & & \\
\hline $1 \mathrm{~A}$ & $\begin{array}{l}\text { Menggunakan berbagai material untuk menghindari efek heat } \\
\text { island pada area atap gedung sehingga nilai albedo (daya refleksi } \\
\text { panas matahari) minimum } 0,3 \text { sesuai dengan perhitungan }\end{array}$ & $\checkmark$ & & \\
\hline & Atau & & & 1 \\
\hline $1 \mathrm{~B}$ & $\begin{array}{l}\text { Menggunakan green roof sebesar } 50 \% \text { dari luas atap yang tidak } \\
\text { digunakan untuk mechanical electrical (ME), dihitung dari luas } \\
\text { tajuk }\end{array}$ & & $\checkmark$ & \\
\hline 2 & $\begin{array}{l}\text { Menggunakan berbagai material untuk menghindari efek heat } \\
\text { island pada area perkerasan non-atap sehingga nilai albedo (daya } \\
\text { refleksi panas matahari) minimum } 0,3 \text { sesuai dengan perhitungan }\end{array}$ & $\checkmark$ & & 1 \\
\hline ASD7 & Manajemen Air Limpasan Hujan & & & \\
\hline $1 \mathrm{~A}$ & $\begin{array}{l}\text { Pengurangan beban volume limpasan air hujan ke jaringan } \\
\text { drainase kota dari lokasi bangunan hingga } 50 \% \text {, yang dihitung } \\
\text { menggunakan nilai intensitas curah hujan sebesar } 50 \mathrm{~mm} / \mathrm{hari} \\
\text { Atau }\end{array}$ & $\checkmark$ & & 1 \\
\hline $1 \mathrm{~B}$ & $\begin{array}{l}\text { Pengurangan beban volume limpasan air hujan ke jaringan } \\
\text { drainase kota dari lokasi bangunan hingga } 85 \% \text {, yang dihitung } \\
\text { menggunakan nilai intensitas curah hujan sebesar } 50 \mathrm{~mm} / \mathrm{hari}\end{array}$ & & $\checkmark$ & 0 \\
\hline 2 & $\begin{array}{l}\text { Menunjukkan adanya upaya penanganan pengurangan beban } \\
\text { banjir lingkungan dari luar lokasi bangunan. }\end{array}$ & $\checkmark$ & & 1 \\
\hline 3 & $\begin{array}{l}\text { Menggunakan teknologi-teknologi yang dapat mengurangi debit } \\
\text { limpasan air hujan. }\end{array}$ & $\checkmark$ & & 1 \\
\hline
\end{tabular}

2. Kategori Efisiensi dan Konversi Energi, sesuai Tabel 4.

Tabel 4. Ringkasan Kategori Efisiensi dan Konversi Energi

\begin{tabular}{|c|c|c|c|c|}
\hline \multirow{2}{*}{ NO } & \multirow{2}{*}{ Kriteria } & \multicolumn{3}{|c|}{ Memenuhi } \\
\hline & & Ya & Tidak & Poin \\
\hline EEC1 & Efisiensi dan Konservasi Energi & & & \\
\hline & Menggunakan Energy modelling software untuk menghitung & & & \\
\hline & konsumsi energi di gedung baseline dan gedung designed. Selisih & & & \\
\hline $1 \mathrm{~A}$ & $\begin{array}{l}\text { konsumsi energi dari gedung baseline dan designed merupakan } \\
\text { penghematan. Untuk setiap penghematan sebesar } 2,5 \% \text {, yang } \\
\text { dimulai dari penurunan energi sebesar } 10 \% \text { dari gedung baseline, } \\
\text { mendapat nilai } 1 \text { nilai (wajib untuk platinum). }\end{array}$ & & $\checkmark$ & 0 \\
\hline & Atau & & & \\
\hline & $\begin{array}{l}\text { Menggunakan perhitungan worksheet, setiap penghematan } 2 \% \\
\text { dari selisih antara gedung designed dan baseline mendapat nilai } 1\end{array}$ & & & \\
\hline 1B & $\begin{array}{l}\text { nilai. Penghematan mulai dihitung dari penurunan energi sebesar } \\
10 \% \text { dari gedung baseline. Worksheet yang dimaksud disediakan } \\
\text { oleh atau GBCI. }\end{array}$ & & $\checkmark$ & 0 \\
\hline EEC2 & Pencahayaan Alami & & & \\
\hline & Penggunaaan cahaya alami secara optimal sehingga minimal & & & \\
\hline 1 & $\begin{array}{l}30 \% \text { luas lantai yang digunakan untuk bekerja mendapatkan } \\
\text { intensitas cahaya alami }\end{array}$ & $\checkmark$ & & 2 \\
\hline 2 & $\begin{array}{l}\text { Jika butir satu dipenuhi lalu ditambah dengan adanya lux } \\
\text { sensor untuk otomatisasi pencahayaan buatan apabila intensitas } \\
\text { cahaya alami kurang dari } 300 \text { lux, didapatkan tambahan } 2 \text { nilai }\end{array}$ & & $\checkmark$ & 0 \\
\hline
\end{tabular}




\begin{tabular}{|c|c|c|c|c|}
\hline \multirow{2}{*}{ NO } & \multirow{2}{*}{ Kriteria } & \multicolumn{3}{|c|}{ Memenuhi } \\
\hline & & Ya & Tidak & Poin \\
\hline EEC3 & Ventilasi & & & \\
\hline 1 & $\begin{array}{l}\text { Tidak mengkondisikan (tidak memberi AC) ruang WC, tangga, } \\
\text { koridor, dan lobi lift, serta melengkapi ruangan tersebut dengan } \\
\text { ventilasi alami ataupun mekanik. }\end{array}$ & $\checkmark$ & & 1 \\
\hline EEC4 & $\begin{array}{l}\text { Pengaruh Perubahan Iklim } \\
\text { Menyerahkan perhitungan pengurangan emisi } \mathrm{CO} 2 \text { yang }\end{array}$ & & & \\
\hline 1 & $\begin{array}{l}\text { didapatkan dari selisih kebutuhan energi antara gedung designed } \\
\text { dan gedung baseline dengan menggunakan grid emission factor }\end{array}$ & & $\checkmark$ & 0 \\
\hline EEC5 & Energi Terbarukan dalam Tapak & & & \\
\hline 1 & Menggunakan sumber energi baru dan terbarukan. & $\checkmark$ & & 5 \\
\hline
\end{tabular}

3. Kategori Kategori Konservasi Air, sesuai Tabel 5

Tabel 5. Ringkasan Kategori Pengurangan Penggunaan Air

\begin{tabular}{|c|c|c|c|c|}
\hline \multirow{2}{*}{ NO } & \multirow{2}{*}{ Kriteria } & \multicolumn{3}{|c|}{ Memenuhi } \\
\hline & & Ya & Tidak & Poin \\
\hline WAC1 & Pengurangan Penggunaan Air & & & \\
\hline 1 & $\begin{array}{l}\text { Konsumsi air bersih dengan jumlah tertinggi } 80 \% \text { dari sumber primer } \\
\text { tanpa mengurangi jumlah kebutuhan per orang }\end{array}$ & $\checkmark$ & & 1 \\
\hline 2 & $\begin{array}{l}\text { Setiap penurunan konsumsi air bersih dari sumber primer sebesar } 5 \% \\
\text { sesuai dengan acuan pada tolok ukur } 1 \text { akan mendapatkan } 1 \text { nilai dengan } \\
\text { dengan nilai maksimum sebesar } 7 \text { nilai. }\end{array}$ & $\checkmark$ & & 7 \\
\hline WAC2 & Fitur Air & & & \\
\hline $1 \mathrm{~A}$ & $\begin{array}{c}\text { Penggunaan fitur air yang sesuai dengan kapasitas buangan di bawah } \\
\text { standar maksimum kemampuan alat keluaran air sesuai dengan lampiran, } \\
\text { sejumlah minimal 25\% dari total pengadaan produk fitur air. } \\
\text { Atau }\end{array}$ & & $\checkmark$ & 0 \\
\hline 1B & $\begin{array}{c}\text { Penggunaan fitur air yang sesuai dengan kapasitas buangan di bawah } \\
\text { standar maksimum kemampuan alat keluaran air sesuai dengan lampiran, } \\
\text { sejumlah minimal 50\% dari total pengadaan produk fitur air . } \\
\text { Atau }\end{array}$ & & $\checkmark$ & 0 \\
\hline $1 \mathrm{C}$ & $\begin{array}{l}\text { Penggunaan fitur air yang sesuai dengan kapasitas buangan di bawah } \\
\text { standar maksimum kemampuan alat keluaran air sesuai dengan lampiran, } \\
\text { sejumlah minimal } 75 \% \text { dari total pengadaan produk fitur air }\end{array}$ & $\checkmark$ & & 3 \\
\hline WAC3 & Daur Ulang Air & & & \\
\hline 1 & $\begin{array}{l}\text { Penggunaan seluruh air bekas pakai (grey water) yang telah di daur } \\
\text { ulang untuk kebutuhan sistem flushing atau cooling tower. }\end{array}$ & $\checkmark$ & & 2 \\
\hline WAC4 & Sumber Air Alternatif & & & \\
\hline $1 \mathrm{~A}$ & $\begin{array}{l}\text { Menggunakan salah satu dari tiga alternatif sebagai berikut: air } \\
\text { kondensasi AC, air bekas wudhu, atau air hujan. }\end{array}$ & & & \\
\hline & Atau & & & \\
\hline 1B & Menggunakan lebih dari satu sumber air dari ketiga alternatif di atas. & & & \\
\hline $1 \mathrm{C}$ & $\begin{array}{l}\text { Atau } \\
\text { Menggunakan teknologi yang memanfaatkan air laut atau air danau atau } \\
\text { air sungai untuk keperluan air bersih sebagai sanitasi, irigasi }\end{array}$ & $\checkmark$ & & 2 \\
\hline WAC5 & Penampungan Air Hujan & & & \\
\hline $1 \mathrm{~A}$ & $\begin{array}{l}\text { Menyediakan instalasi tangki penampungan air hujan kapasitas } 20 \% \text { dari } \\
\text { jumlah air hujan yang jatuh di atas atap bangunan yang dihitung } \\
\text { menggunakan nilai intensitas curah hujan sebesar } 50 \mathrm{~mm} / \text { hari.. } \\
\text { Atau }\end{array}$ & & & \\
\hline 1B & Menyediakan tangki penampungan air hujan berkapasitas $35 \%$ & & & \\
\hline $1 \mathrm{C}$ & $\begin{array}{l}\text { Atau } \\
\text { Menyediakan instalasi tangki penampungan air hujan berkapasitas 50\% dari } \\
\text { perhitungan di atas. }\end{array}$ & $\checkmark$ & & 3 \\
\hline WAC6 & Efisiensi Penggunaan Air Lansekap & & & \\
\hline 1 & $\begin{array}{l}\text { Seluruh air yang digunakan untuk irigasi gedung tidak berasal dari } \\
\text { sumber air tanah dan/atau PDAM. }\end{array}$ & $\checkmark$ & & 1 \\
\hline 2 & $\begin{array}{l}\text { Menerapkan teknologi yang inovatif untuk irigasi yang dapat } \\
\text { mengontrol kebutuhan air untuk lansekap yang tepat, sesuai dengan } \\
\text { kebutuhan tanaman. }\end{array}$ & & $\checkmark$ & 0 \\
\hline
\end{tabular}


4. Kategori Sumber dan Siklus Material, sesuai Tabel 6.

Tabel 6. Ringkasan Kategori Sumber dan Siklus Material

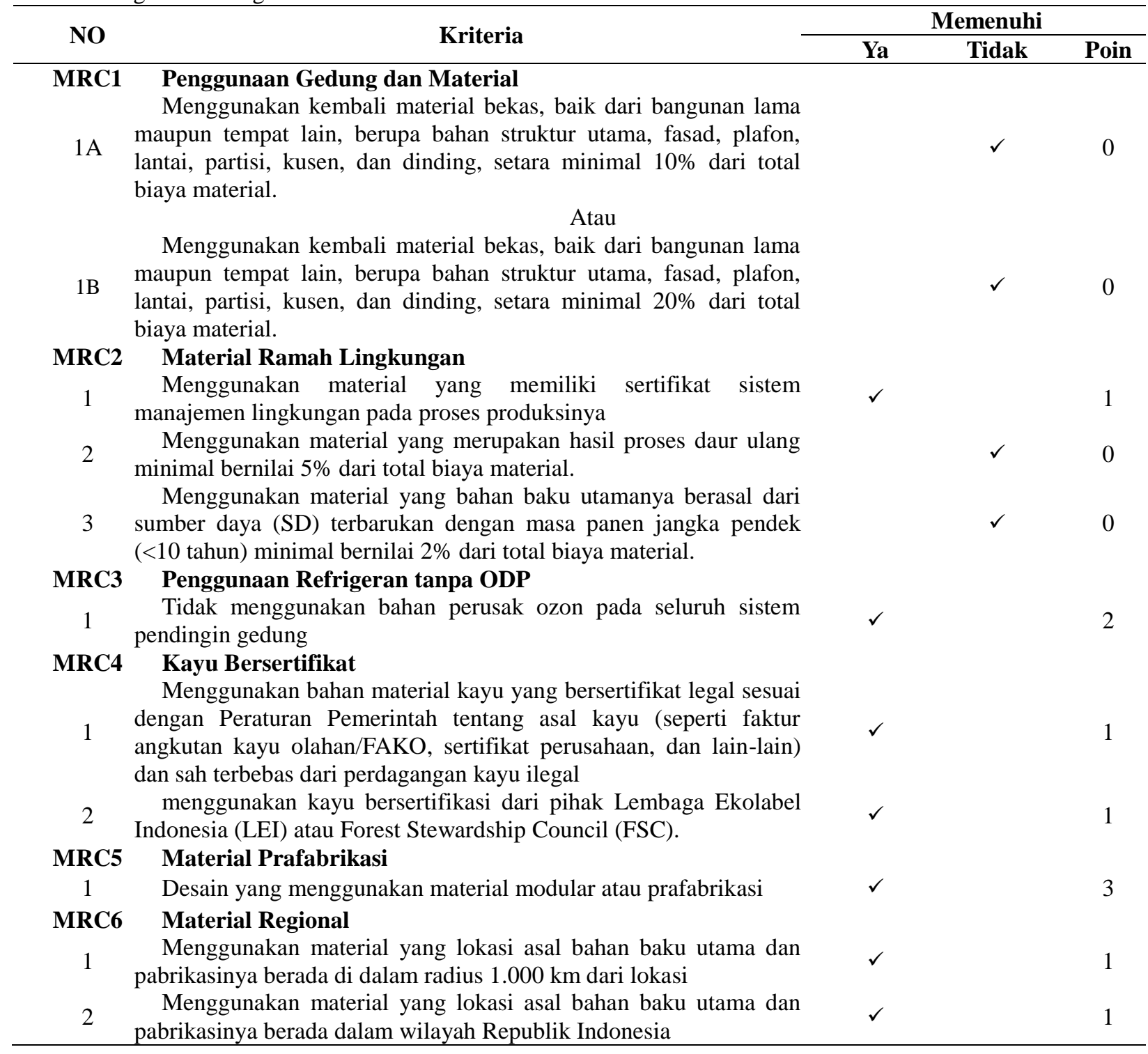

5. Kategori Kesehatan dan Kenyamanan dalam Ruang, sesuai Tabel 7.

Tabel 7. Ringkasan Kategori Kesehatan dan Kenyamanan dalam Ruang

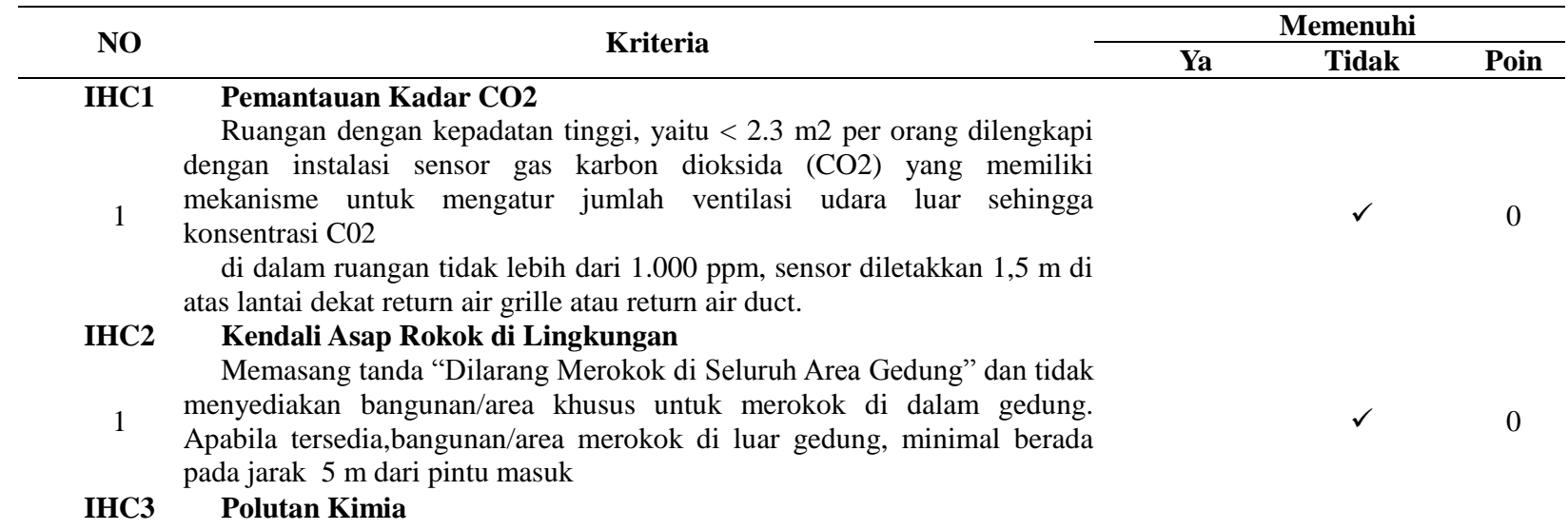




\begin{tabular}{|c|c|c|c|c|}
\hline \multirow{2}{*}{ NO } & \multirow{2}{*}{ Kriteria } & \multicolumn{3}{|c|}{ Memenuhi } \\
\hline & & Ya & Tidak & Poin \\
\hline 1 & $\begin{array}{l}\text { Menggunakan cat dan coating yang mengandung kadar volatile organic } \\
\text { compounds (VOCs) rendah, yang ditandai dengan label/sertifikasi. }\end{array}$ & $\checkmark$ & & 1 \\
\hline 2 & $\begin{array}{l}\text { Menggunakan produk kayu komposit dan laminating adhesive dengan } \\
\text { syarat memiliki kadar emisi formaldehida rendah, yang ditandai dengan } \\
\text { label/sertifikasi yang diakui GBC Indonesia }\end{array}$ & $\checkmark$ & & 1 \\
\hline 3 & Menggunakan material lampu yang tidak mengandung merkuri & $\checkmark$ & & 1 \\
\hline IHC4 & Pemandangan keluar Gedung & & & \\
\hline 1 & $\begin{array}{l}\text { Adanya akses menghadap langsung ke pemandangan luar yang dibatasi } \\
\text { bukaan transparan. }\end{array}$ & $\checkmark$ & & 1 \\
\hline IHC5 & Kenyamanan Visual & & & \\
\hline 1 & $\begin{array}{l}\text { Menggunakan lampu dengan iluminansi (tingkat pencahayaan) ruangan } \\
\text { sesuai dengan SNI 03-6197-2011 tentang Konservasi Energi pada Sistem } \\
\text { Pencahayaan }\end{array}$ & $\checkmark$ & & 1 \\
\hline IHC6 & Kenyamanan Termal & & & \\
\hline 1 & $\begin{array}{l}\text { Menetapkan perencanaan kondisi termal secara umum pada suhu } 25^{\circ} \mathrm{C} \\
\text { dan kelembaban relatif } 60 \%\end{array}$ & $\checkmark$ & & 1 \\
\hline IHC7 & Tingkat Kebisingan & & & \\
\hline 1 & $\begin{array}{l}\text { Tingkat kebisingan tidak lebih dari atau sesuai dengan SNI 03-6386- } \\
2000 \text { tentang Spesifikasi Tingkat Bunyi dan Waktu Dengung dalam } \\
\text { Bangunan Gedung dan Perumahan (kriteria desain yang direkomendasikan) }\end{array}$ & $\checkmark$ & & 1 \\
\hline
\end{tabular}

6. Kategori Manajemen Lingkungan Bangunan, sesuai Tabel 8.

Tabel 8. Ringkasan Kategori Manajemen Lingkungan Bangunan

\begin{tabular}{|c|c|c|c|c|}
\hline \multirow[b]{2}{*}{ NO } & \multirow{2}{*}{ Kriteria } & \multicolumn{3}{|c|}{ Memenuhi } \\
\hline & & Ya & Tidak & Poin \\
\hline BEM1 & $\begin{array}{l}\text { GP Sebagai Anggota Tim Proyek } \\
\text { Melibatkan minimal seorang tenaga ahli yang sudah bersertifikat }\end{array}$ & & & \\
\hline 1 & $\begin{array}{l}\text { GREENSHIP Professional (GP), yang bertugas untuk memandu proyek } \\
\text { hingga mendapatkan sertifikat GREENSHIP. }\end{array}$ & $\checkmark$ & & 1 \\
\hline BEM2 & Polusi dari Aktivitas Konstruksi & & & \\
\hline 1 & $\begin{array}{l}\text { Limbah padat, dengan menyediakan area pengumpulan, pemisahan, } \\
\text { dan sistem pencatatan. Pencatatan dibedakan berdasarkan limbah padat } \\
\text { yang dibuang ke TPA, digunakan kembali, dan didaur ulang oleh pihak } \\
\text { ketiga. }\end{array}$ & $\checkmark$ & & 1 \\
\hline 2 & $\begin{array}{l}\text { Limbah cair, dengan menjaga kualitas seluruh buangan air yang timbul } \\
\text { dari aktivitas konstruksi agar tidak mencemari drainase kota }\end{array}$ & $\checkmark$ & & 1 \\
\hline BEM3 & Pengelolaan Sampah Tingkat Lanjut & & & \\
\hline - & $\begin{array}{l}\text { Mengolah limbah organik gedung yang dilakukan secara mandiri } \\
\text { maupun bekerjasama dengan pihak ketiga sehingga menambah nilai } \\
\text { manfaat dan mengurangi dampak lingkungan. }\end{array}$ & $\checkmark$ & & 1 \\
\hline 2 & $\begin{array}{l}\text { Mengolah limbah anorganik gedung yang dilakukan secara mandiri } \\
\text { maupun bekerjasama dengan pihak ketiga sehingga menambah nilai } \\
\text { manfaat dan dapat mengurangi dampak lingkungan. }\end{array}$ & $\checkmark$ & & 1 \\
\hline BEM4 & $\begin{array}{l}\text { Sistem Komisioning yang Baik dan Benar } \\
\text { Melakukan prosedur testing- commissioning, termasuk pelatihan }\end{array}$ & & & \\
\hline 1 & $\begin{array}{l}\text { terkait untuk optimalisasi kesesuaian fungsi dan kinerja peralatan/sistem } \\
\text { dengan perencanaan dan acuannya. }\end{array}$ & $\checkmark$ & & 1 \\
\hline 2 & $\begin{array}{l}\text { Memastikan seluruh measuring adjusting instrument telah terpasang } \\
\text { pada saat konstruksi dan memperhatikan kesesuaian antara desain dan } \\
\text { spesifikasi teknis terkait komponen proper commissioning. }\end{array}$ & $\checkmark$ & & 1 \\
\hline BEM5 & Penyerahan Data Green Building & & & \\
\hline 1 & $\begin{array}{l}\text { Menyerahkan data implementasi green building sesuai dengan form } \\
\text { dari GBC Indonesia. }\end{array}$ & & $\checkmark$ & 0 \\
\hline 2 & $\begin{array}{l}\text { Memberi pernyataan bahwa pemilik gedung akan menyerahkan data } \\
\text { implementasi green building dari bangunannya dalam waktu } 12 \text { bulan } \\
\text { setelah tanggal sertifikasi kepada GBC Indonesia dan suatu pusat data } \\
\text { energi Indonesia yang akan ditentukan kemudian }\end{array}$ & & $\checkmark$ & 0 \\
\hline BEM6 & $\begin{array}{l}\text { Kesepakatan Dalam Melakukan Aktivitas Fit Out } \\
\text { Memiliki surat perjanjian dengan penyewa gedung (tenant) untuk }\end{array}$ & & & \\
\hline 1 & $\begin{array}{l}\text { gedung yang disewakan atau POS untuk gedung yang digunakan sendiri, } \\
\text { yang terdiri atas: } \\
\text { a. Penggunaan kayu yang bersertifikat untuk material fit-out }\end{array}$ & & $\checkmark$ & 0 \\
\hline
\end{tabular}




\begin{tabular}{|c|c|c|c|c|}
\hline \multirow{2}{*}{ NO } & \multirow{2}{*}{ Kriteria } & \multicolumn{3}{|c|}{ Memenuhi } \\
\hline & & Ya & Tidak & Poin \\
\hline & $\begin{array}{l}\text { b. Pelaksanaan pelatihan yang akan dilakukan oleh manajemen gedung } \\
\text { c. Pelaksanaan manajemen indoor air quality (IAQ) setelah konstruksi fit- } \\
\text { out. Implementasi dalam bentuk Perjanjian Sewa (lease agreement) atau } \\
\text { POS. }\end{array}$ & & & \\
\hline BEM7 & $\begin{array}{l}\text { Survei Pengguna Gedung } \\
\text { Memberi pernyataan bahwa pemilik gedung akan mengadakan survei } \\
\text { suhu dan kelembaban paling lambat } 12 \text { bulan setelah tanggal sertifikasi } \\
\text { dan menyerahkan laporan hasil survei paling lambat } 15 \text { bulan setelah }\end{array}$ & & & \\
\hline 1 & $\begin{array}{l}\text { tanggal sertifikasi kepada GBC Indonesia. Catatan: Apabila hasilnya lebih } \\
\text { dari } 20 \% \text { responden menyatakan ketidaknyamanannya, maka pemilik } \\
\text { gedung setuju untuk melakukan perbaikan selambat-lambatnya } 6 \text { bulan } \\
\text { setelah pelaporan hasil survei. }\end{array}$ & & $\checkmark$ & 0 \\
\hline
\end{tabular}

\section{SIMPULAN}

Dari analisis dan penilaian kriteria Green and Smart Building berdasarkan perangkat penilaian Greenship untuk bangunan baru versi 1.2 yang telah dilakukan pada Gedung Kantor PT. INALUM (Persero) diperoleh kesimpulan bahwa Gedung Kantor PT. INALUM (Persero) memenuhi seluruh syarat kelayakan bangunan berdasarkan Greenship untuk bangunan baru versi 1.2 dan Gedung Kantor PT. INALUM (Persero) memenuhi 7 (tujuh) dari 8 (delapan) kriteria prasyarat berdasarkan Greenship untuk bangunan baru versi 1.2. dan Gedung Kantor PT. INALUM (Persero) memperoleh 66 poin dari tolal 101 poin maksimal dan memperoleh persentase sebesar 65,35\%. Berdasarkan tingkat predikat Greenship yang dikeluarkan oleh GBC Indonesia, Gedung Kantor PT. INALUM (Persero) memperoleh predikat emas.

\section{DAFTAR PUSTAKA}

Aryani, Y., (2011), Dampak Bangunan Terhadap Lingkungan, online https://udararuang.wordpress.com/2011/10/26/dampak-bangunan-terhadap-lingkungan/.

Green Building Council Indonesia, (2013), Greenship untuk Gedung Baru Versi 1.2, online https://www.gbcindonesia.org/download/doc_download/125-ringkasan-greenship-nb-v1-2-id.

Green Building Council Indonesia, (2018), Achievement of Green Building Council Indonesia 2017-2018, online http://www.gbcindonesia.org/download/doc_download/167-achievement-of-greenbuilding-council-indonesia-2017-2018.

Kementerian Pekerjaan Umum dan Perumahan Rakyat Direktorat Jenderal Cipta Karya Direktorat Bina Penataan Bangunan, (2019), Peran Kementerian PUPR dalam Penerapan Green \& Smart Building di Indonesia, Temu Wicara Nasional Forum Komunikasi Mahasiswa Teknik Sipil Indonesia, November 12-13, Jakarta.

Kementerian Pekerjaan Umum dan Perumahan Rakyat Direktorat Jenderal Cipta Karya Direktorat Bina Penataan Bangunan, (2019), Green \& Smart Building, Temu Wicara Nasional Forum Komunikasi Mahasiswa Teknik Sipil Indonesia, November 12-13, Jakarta. 
Nababan, Ribka Vitoria, (2019), Analisis Penerapan Green Building pada Gedung Perkuliahan Universitas Islam Negeri Sumatera Utara, Skripsi, Departemen Teknik Sipil, Fakultas Teknik, Universitas Sumatera Utara, Medan.

PERMEN PUPR Nomor 02/PRT/M/2015 tentang Bangunan Gedung Hijau.

Sari, Suci Anugrah, (2016), Penilaian Kriteria Green Building pada Bangunan Gedung (Studi Kasu: Gedung Biro Pusat Administrasi Universitas Sumatera Utara), Skripsi, Departemen Teknik Sipil, Fakultas Teknik, Universitas Sumatera Utara, Medan.

Undang-Undang No. 28 Tahun 2002 tentang Bangunan Gedung 